\title{
X-Ray Computed Tomography for Root Quantification
}

\author{
Bente Foereid \\ Environment and Climate Division, NIBIO, Ås, Norway \\ Email: bente.foereid@bioforsk.no
}

Received 4 June 2015; accepted 4 July 2015; published 7 July 2015

Copyright ( 2015 by author and Scientific Research Publishing Inc.

This work is licensed under the Creative Commons Attribution International License (CC BY). http://creativecommons.org/licenses/by/4.0/

(c) (i) Open Access

\begin{abstract}
Soil cores from a field growing barley and barley mutants without root hairs under conventional and minimum tillage were sampled. They were $X$-ray scanned to produce a $3 D$ image and then the roots were washed out and weight and length were determined by conventional means. Root volume and surface area were then calculated from the 3D images using state of the art software and methodology, and the measured and calculated measures were correlated. The only strong and significant correlation was between measured weight and calculated volume for mutants without root hairs. It is concluded that the software cannot segment out very small roots, but segmentation accuracy also depends on root structure in some unknown way. Any study using X-ray computed tomography to quantify roots as they grow in situ should start with a calibration for the conditions in question.
\end{abstract}

\section{Keywords}

Roots, 3D Image, X-Ray Computed Tomography

\section{Introduction}

Whilst aboveground plant development and productivity can usually be easily observed and quantified, at least on the plot scale, quantification of roots still pose significant challenges. None of the methods available can quantify root biomass or turnover reliably. Furthermore, most methods are destructive, and there are few methods available to observe roots as they grow.

$\mathrm{X}$-ray CT was first developed for medical applications, and was later used for a variety of industrial applications. The development scanners that could scan a variety of size classes, including small ones (micro-tomography) made it useful also for geological applications, including soils [1]. X-ray CT has had a variety of useful applications in studies of soil physics (e.g. [2]-[6]), but studies of biological properties have turned out to be dif- 
ficult as organic matter has a similar X-ray attenuation as air [7].

Although imaging roots using X-ray CT can be challenging because roots are difficult to distinguish from pores, progress has been made [8]. The power of the technology lies in that the method is non-destructive, so that roots can be observed repeatedly over time as they grow. Some progress has been made in segmenting soil from pore space [9]-[11]. Segmentation of roots has also been attempted, but has so far succeeded for very young roots or small parts of roots [12] [13].

In 3D scans of roots in soil the roots can be segmented out and volume and surface area can be calculated using dedicated software. However, it is not known how accurate these measures are. The purpose of this paper is to compare surface and volume calculated by software on 3D scans to weight the length of roots measured by traditional destructive techniques on roots washed out from the samples after scanning.

\section{Materials and Methods}

\subsection{Field Experiment}

The field experiment was established in Invergowrie, Dundee, Scotland, UK $\left(56^{\circ} 27^{\prime} \mathrm{N}, 3^{\circ} \mathrm{W}\right)$ in 2003 (see [14] for details) to compare tillage treatments, among them conventional and minimum tillage. The field was situated in a mainly agricultural area in eastern Scotland close to the sea. The soil was Dystric-Fluvic Cambisol (FAO) with a sandy-loam texture. It had a $\mathrm{pH}$ (1 part soil to 2.5 parts $1 \mathrm{M} \mathrm{CaCl}_{2}$ ) of 5.7, was freely drained and underlain by colluvial sand at $60 \mathrm{~cm}$ depth. In 2012 the fields were planted to barley with different rooting pattern, among them wild type and a mutant lacking root hairs. The mutants and their origin are described in [15].

\subsection{Sampling and Direct Root Measurements}

Soil cores were sampled in plastic rings $(4 \mathrm{~cm}$ height, $4 \mathrm{~cm}$ diameter). Before sampling, aboveground plant material and top soil were removed in the area to be sampled, so that the sampling depth was $4-8 \mathrm{~cm}$. To make sure all samples were fresh when scanned and processed, each replicate $(\mathrm{n}=3)$ were sampled on different days. Sampling days were $21,23,25$ May. The samples were stored in a cold store $\left(4^{\circ} \mathrm{C}\right)$ until scanning (after 1 day) and further sample processing (after 2 days). The treatments sampled were barley mutants without root hairs and the wild type (with root hairs) at minimum and conventional tillage.

Roots were washed out, and total roots length was determined by scanning the roots and using the software WinRhizo. The roots were then dried at $70^{\circ} \mathrm{C}$ overnight and dry weight determined.

\subsubsection{Scanning Specifications and Root Segmentation Method}

$3 \mathrm{D}$ volumetric images in this study were obtained using a Metris X-Tek HMX CT scanner with a Varian Paxscan $2520 \mathrm{~V}$ detector and a $225 \mathrm{kV}$ X-ray source (Nikon Metrology X-Tek Systems Ltd, Tring, UK) giving a resolution of up to $5 \mu \mathrm{m}$. Samples were scanned at $160 \mathrm{kV}$ and $201 \mathrm{~mA}$ using a $0.1 \mathrm{~mm}$ Al filter to obtain 3003 angular projections (based on a $360^{\circ}$ rotation).

VGStudio MAX 2.2 (Volume Graphics, Germany) was used for root segmentation. Roots were identified by eye, and segmented using "region grower". This was repeated several times in each sample until no more roots could be found. Erode/dilate (radius 2) was then used. The total volume and surface of the root region was calculated by the software. The procedure was repeated twice for each sample, to assess repeatability of the procedure.

\subsubsection{Statistics}

Minitab v15 was used. Correlation analyses between root weight (measured by weighing) and root volume (calculated by VGStudioMAX) and between root length (measured by WinRhizo) and root surface area (calculated by VGStudioMAX) and between root surface area measured by WinRhizo and calculated by VGstudioMax were performed. Varieties with and without root hairs were correlated separately.

\section{Results and Discussion}

It was expected that weight and volume of roots would be strongly correlated, and that testing if the volume measured in the 3D image correlates with the weight should be a good test of the calculation from the 3D image. Root length and surface area were also expected to be correlated, but this correlation was expected to be weaker. 
Overall there was little correlation between measurements done on the roots and the parameters calculated from the 3D image (Table 1; Figure 1). The only strong and significant correlation was between measured weight and calculated volume for the varieties without root hairs showed (Table 1; Figure 1). Tillage treatment did not affect the relationship between measured and calculated parameters, but variety (with or without root hairs) did (Figure 1). How well roots can be quantified from 3D images therefore depends on the type or structure of the roots. Hirano et al. [16] found that detection frequency of roots below $1 \mathrm{~cm}$ in diameter was poor using root penetrating radar. Also in this study it was noted that very thin roots were not picked up by the software even when they were seen by the experimenter. Large roots or high resolution would help, but that means that with current technology only a small volume of soil can be examined. Any use of 3D imagery in following root development should start with a calibration like this for the type of roots and resolution to be used. Using a homogenous soil may also help, but the results here suggest that the quality of the roots are more important. It is not known why the roots without root hairs were easier to quantify. Although root hair are too small to be seen on a 3D image, they are also lost in root washing, so they would also not be included in the weight measurements. It is possible that varieties without root hairs compensate by being thicker or in other ways more distinct, and therefore easier for the software to follow.

\section{Conclusion}

Larger roots can be reliably quantified in 3D X-ray images, but the quantification is less reliable for smaller roots. However, reliability also depends on root structure in a way that is not fully understood, and any study of in situ root growth using X-ray tomography should start with a calibration of reliability for the roots and resolution to be used.

Table 1. Pearson's correlation coefficient and p-values for correlations between various parameters measured and calculated from the X-ray CT scans.

\begin{tabular}{|c|c|c|c|c|c|c|}
\hline & \multicolumn{2}{|c|}{ Overall } & \multicolumn{2}{|c|}{ Varieties with root hair } & \multicolumn{2}{|c|}{ Varieties without root hair } \\
\hline & $\mathrm{R}$ & $\mathrm{p}$ & $\mathrm{R}$ & $\mathrm{p}$ & $\mathrm{R}$ & $\mathrm{p}$ \\
\hline Weight vs. volume & 0.454 & 0.138 & 0.362 & 0.481 & 0.823 & 0.044 \\
\hline Surface vs. length & 0.159 & 0.622 & 0.052 & 0.923 & 0.388 & 0.447 \\
\hline Surface, measured vs. calculated & 0.210 & 0.512 & -0.442 & 0.380 & 0.441 & 0.381 \\
\hline
\end{tabular}

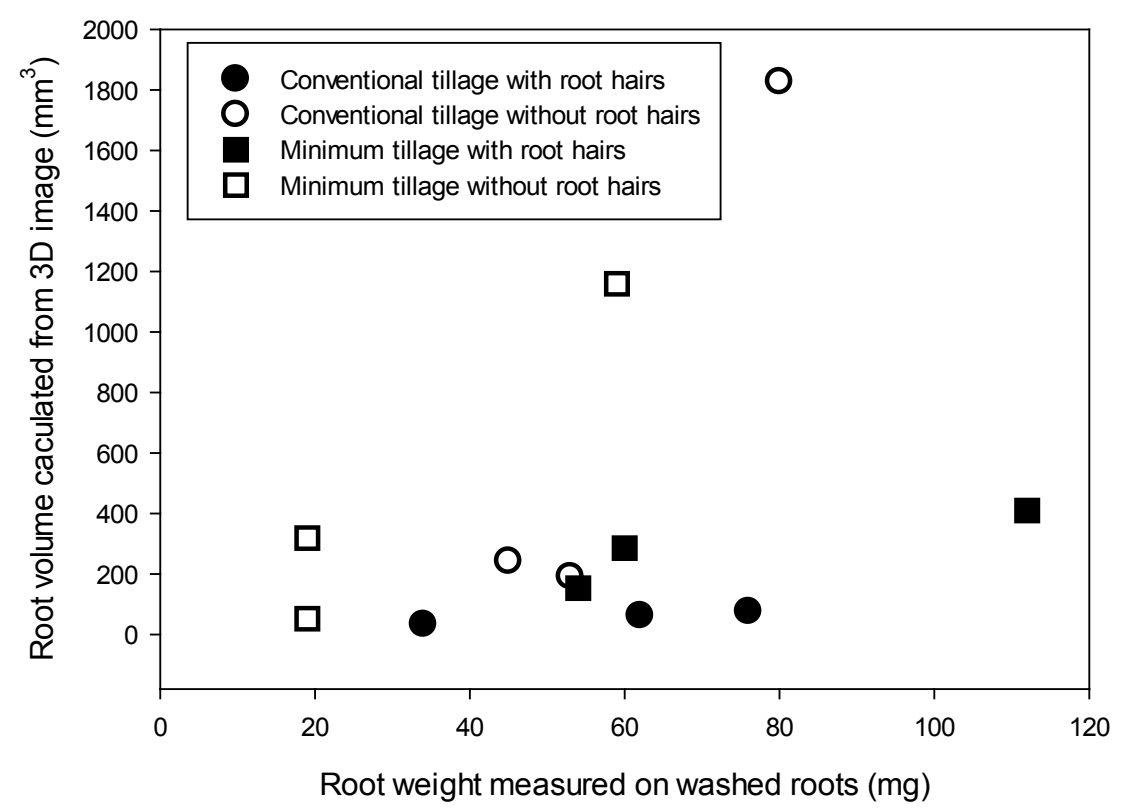

Figure 1. Root weight measured plotted against root volume calculated from the 3D image for the two tillage treatments and two varieties. 


\section{Acknowledgements}

The author wishes to thank Dr. Tim George at James Hutton Institute in Dundee, UK for support at the field site VGstudioMAX support team in Heidelberg, Germany for support on the use of the software. This work was supported by the University of Abertay Dundee, UK.

\section{References}

[1] Ketcham, R.A. and Carlson, W.D. (2001) Acquisition, Optimization and Interpretation of X-Ray Computed Tomographic Imagery: Applications to the Geosciences. Computers and Geosciences, 27, 381-400. http://dx.doi.org/10.1016/S0098-3004(00)00116-3

[2] De Gryze, S., Jassogne, L., Six, J., Bossuyt, H., Wevers, M. and Merckx, R. (2006) Pore Structure Changes during Decomposition of Fresh Residue: X-Ray Tomography Analyses. Geoderma, 134, 82-96. http://dx.doi.org/10.1016/j.geoderma.2005.09.002

[3] Nunan, N., Ritz, K., Rivers, M., Feeney, D.S. and Young, I.M. (2006) Investigating Microbial Micro-Habitat Structure Using X-Ray Computed Tomography. Geoderma, 133, 398-407. http://dx.doi.org/10.1016/j.geoderma.2005.08.004

[4] Sleutel, S., Cnudde, V., Masschaele, B., Vlassenbroek, J., Dierick, M., Van Hoorebeke, L., Jacobs, P. and De Neve, S. (2008) Comparison of Different Nano- and Micro-Focus X-Ray Computed Tomography Set-Ups for the Visualization of the Soil Microstructure and Soil Organic Matter. Computers and Geosciences, 34, 931-938. http://dx.doi.org/10.1016/j.cageo.2007.10.006

[5] Iassonov, P., Gebrenegus, T. and Tuller, M. (2009) Segmentation of X-Ray Computed Tomography Images of Porous Materials: A Crucial Step for Characterization and Quantitative Analysis of Pore Structures. Water Resources Research, 45, W09415. http://dx.doi.org/10.1029/2009WR008087

[6] Elyeznasni, N., Sellami, F., Pot, V., Benoit, P., Vieublé-Gonod, L., Young, I. and Peth, S. (2012) Exploration of Soil Micromorphology to Identify Coarse-Sized OM Assemblages in X-Ray CT Images of Undisturbed Cultivated Soil Cores. Geoderma, 179-180, 38-45. http://dx.doi.org/10.1016/j.geoderma.2012.02.023

[7] Taina, I.A., Heck1, R.J. and Elliot, T.R. (2007) Application of X-Ray Computed Tomography to Soil Science: A Literature Review. Canadian Journal of Soil Science, 88, 1-19. http://dx.doi.org/10.4141/CJSS06027

[8] Mooney, S.J. Pridmore, T.P., Helliwell, J. and Bennett, M.J. (2012) Developing X-Ray Computed Tomography to Non-Invasively Image 3-D Root Systems Architecture in Soil. Plant and Soil, 352, 1-22. http://dx.doi.org/10.1007/s11104-011-1039-9

[9] Hapca, S., Houston, A.N., Otten, W. and Baveye. P. (2013) New Objective Segmentation Method Based on Minimizing Locally the Intra-Class Variance of Grayscale Images. Vadoze Zone, 12, $13 \mathrm{p}$. http://dx.doi.org/10.2136/vzj2012.0172

[10] Houston, A.N., Otten, W., Baveye, P. and Hapca, S. (2013) Thresholding of Computed Tomography Images of Heterogeneous Porous Media by Adaptive-Window Indicator Kriging. Computers and Geosciences, 54, 239-248. http://dx.doi.org/10.1016/j.cageo.2012.11.016

[11] Houston, A.N., Schmidt, S., Otten, W., Baveye, P. and Hapca, S. (2013) Effect of Scanning and Image Reconstruction Settings in X-Ray Computed Tomography on Soil Image Quality and Segmentation Performance. Geoderma, 207-208, 154-165. http://dx.doi.org/10.1016/j.geoderma.2013.05.017

[12] Schmidt, S. Bengough, A.G., Gregory, P.J., Grinev, D.V. and Otten, W. (2012) Estimating Root-Soil Contact from 3-D X-Ray Microtomography. European Journal of Soil Science, 63, 776-786. http://dx.doi.org/10.1111/j.1365-2389.2012.01487.x

[13] Haling, R.E., Tighe, M.K., Flavel, R.J. and Young, I.M. (2013) Application of X-Ray Computed Tomography to Quantify Fresh Root Decomposition in Situ. Plant and Soil, 372, 619-627. http://dx.doi.org/10.1007/s11104-013-1777-y

[14] Sun, B., Hallett, P.D., Caul, S., Daniell, T.J. and Hopkins, D.W. (2011) Distribution of Soil Carbon and Microbial Biomass in Arable Soils under Different Tillage Regimes. Plant and Soil, 338, 17-25. http://dx.doi.org/10.1007/s11104-010-0459-2

[15] Brown, L.K., George, T.S., Barrett, G.E., Hubbard, S.F. and White, P.J. (2013) Interactions between Root Hair Length and Arbuscular Mycorrhizal Colonization in Phosphorus Deficient Barley (Hordeum vulgare). Plant and Soil, 372, 195-205. http://dx.doi.org/10.1007/s11104-013-1718-9

[16] Hirano, Y., Yamamoto, R., Dannoura, M., Aono, K., Igarashi, T., Ishii, M., Yamase, K., Makita, N. and Kanazawa, Y. (2012) Detection Frequency of Pinus thunbergii Roots by Ground-Penetrating Radar Is Related to Root Biomass. Plant and Soil, 360, 363-373. http://dx.doi.org/10.1007/s11104-012-1252-1 